\title{
Maths Advice and Revision for Chemistry (MARC)
}

\author{
Beth Paschke \& Shazia Ahmed
}

University of Glasgow

*Corresponding Author: Beth.Paschke@glasgow.ac.uk

Keywords: Chemistry, Mathematics, Student Support, Maths Support

\begin{abstract}
It has been recognised for some time by Science and Engineering departments that students are entering Higher Education illequipped in terms of their mathematical skills, despite having in many cases, attained good grades at Higher/A level (The Engineering Council 2000; Fry, Ketteridge \& Marshall 1999; Score Education 2009). In an attempt, therefore, to ensure that all students progressing on to Chemistry degrees are equally prepared (in terms of ability and confidence) to attempt the more mathematical aspects of our courses, the School of Chemistry has over recent years been sequentially introducing mathematics support into the curriculum.
\end{abstract}

As part of the School's ongoing mathematical support provision, the aim of this project was two-fold:

1) to assess the popularity and effectiveness of tailored maths support sessions and

2) in relation to the teaching of mathematical concepts to science students, collate examples of existing appropriate open educational resources to provide additional support to facilitate student learning such as RSC Discover Maths for Chemistry and Math Centre (Royal Society of Chemistry; MathCentre 2016).

A pilot project has been carried out during the academic year 2015-2016, where support sessions were delivered in tutorial format by the Maths Adviser. Although the sessions were open to all $3^{\text {rd }}$ year students studying on chemistry degree programmes, the expectation was that they would mainly be attended by students with little formal mathematics training and those who are less confident about their abilities.

\section{Background}

Confidence and ability with mathematics is absolutely necessary to explore important concepts and calculations in chemistry. Without basic mathematical skills, these aspects, and therefore chemistry itself, will be extremely difficult. This is not just a concern for the teaching of chemistry at the University of Glasgow (Shallcross \& Yates 2014; Gagan 2008). In response, most chemistry degree programmes request a minimum qualification in mathematics as a pre-entry requirement or include compulsory university level mathematics as part of their degree course (Shallcross \& Yates 2014).

The College-entry system at the University of Glasgow offers flexibility and choice to our students, which means a pre-entry mathematics grade is not necessarily held by students in the School of Chemistry and attendance at compulsory mathematics classes is currently not required. The advantage of this system is that this gives our students the flexibility to transfer between programmes if they choose to do so, but disadvantages them at level 3 when complex mathematical concepts such as quantum chemistry, molecular symmetry and 
kinetics are covered. Hence some students entering our chemistry courses are quite apprehensive about and unprepared for the more challenging mathematical aspects of our degrees.

In an attempt, therefore, to ensure that all students progressing on to Chemistry degrees at the University of Glasgow are equally prepared (in terms of ability and confidence) to attempt the more mathematical aspects of our courses, the School of Chemistry has over recent years been sequentially introducing maths support into our curriculum.

\section{Maths in Chemistry at Glasgow \\ The mathematical content at present comprises:}

1) At level 1, students can complete a voluntary section consisting of basic mathematical techniques in their laboratory manual. In addition, they attend two lectures on data analysis.

2) At level 2, students formerly attended six hours of laboratory based workshops covering topics such as basic algebra, arithmetic, logarithms and exponentials. These have been converted to Moodle quizzes since 2014.

3) Until 2012, level 3 students attended 4 $\times 1$ hour long full class workshops. As the class size was very large, it was difficult to identify and adequately support students with a weak mathematical background. It was decided therefore to split the class up into smaller groups for tutorials in order to address the range of backgrounds and abilities in Mathematics. Despite this, many students were not equipped to confidently tackle the tutorials. For this reason, in 2015, Maths Advice and Revision in Chemistry (MARC) sessions were trialled to support this group of students.

\section{MARC Sessions}

The Student Learning Service (SLS) is a centrally located service within the university. The Maths Adviser from SLS was enlisted to provide the additional, tailored MARC sessions to students.

Firstly, the Maths Adviser was invited to the first chemistry lecture of the academic year to give students information about the support that is available to them through SLS: bookable one-to-one appointments and weekly drop-in sessions. In addition, students were encouraged to attend MARC sessions which were designed to help them tackle the tutorial problems by giving them an introduction to the forthcoming maths topic.

Since the student population at the University of Glasgow has historically consisted of a high proportion of Scottish school leavers, our expectation was that the majority of the cohort would predominantly have a Higher Maths qualification, with a smaller number having a GCSE or Standard Grade. For this reason, it was decided to strategically choose topics to which that they would have had limited exposure. Two sessions, 'Complex Numbers' and 'Vectors and Matrices', took place in the first semester and one in the second semester, 'Differentiation and Integration'.

The sessions were carefully timetabled so all students would have the opportunity to attend if they so wished.

\section{Feedlback}

All sessions were unexpectedly popular in that up to one third of the level 3 cohort attended despite attendance at the sessions being voluntary and early in the day prior to the start of other classes. Also unexpectedly, almost $85 \%$ of those who attended already had satisfactory mathematical qualifications appropriate for their chemistry course. The feedback was generally very positive. With hindsight, the students felt that mathematical content should be introduced earlier and some even suggested making it compulsory. Longer sessions were requested, as were separate sessions for each topic (for example, one session for differentiation and another for integration).

\section{Future plans}

In response to feedback, seven MARC sessions have been scheduled for the academic year 2016-17: Logarithms and 
Exponentials, Trigonometric Functions, Complex Numbers, Vectors and Matrices, Differentiation, Integration and Differential Equations.

With the view to introducing mathematical concepts and support at an earlier stage in their degree, from academic year 2016-17, the level 2 Moodle quizzes are being introduced to level 1 Chemistry students. From next year (2017-18), we plan to move part of the current level 3 maths tutorial materials into level 2 in order to continue with our sequential introduction of mathematics into the curriculum and to build upon the knowledge that has already been introduced (Shallcross \& Yates 2014, Gagan 2008; Biggs \& Tang 2011). A minimum entry requirement of Higher Maths for all Chemistry programmes is also currently under consideration.

Following our successful application to the university's Blended and Online Learning Development (BOLD) initiative, our longer term plans include the introduction of an online mathematical fluency test (in collaboration with the School of Mathematics and Statistics) with data from this to be used to target effective and interactive learning experiences in the form of Peer Assisted Learning for those students who require the most support.

\section{References}

Biggs, J. \& Tang, C. (2011) Teaching for Quality Learning at University $4^{\text {th }}$ edition, McGraw-Hill Education (UK)
Fry, H., Kettridge, S. \& Marshall, S. (2009) A handbook for Teaching and Learning in Higher Education. Kogan Page. http://preview.tinyurl.com//8aqh8g

Gagan (2008) Review of the Student Learning Experience in: CHEMISTRY, Higher Education Academy https://www.heacademy.ac.uk/system/files/ch emrev final.pdf

MathCentre (2016)

www.mathcentre.ac.uk/

Royal Society of Chemistry http://www.rsc.org/

Score Education (2009) Report: GCSE Science 2008 Examination, Gatsby Technical Education Projects. http://www.scoreeducation.org/downloads/gcse project/SCOR E report final.pdf

Shallcross, D.E. \& Yates, P.C. (2014). Skills in Mathematics and Statistics in Chemistry and tackling transition. Higher Education Academy https://www.heacademy.ac.uk/system/files/res ources/tt maths chemistry.pdf

The Engineering Council (2000). Measuring the Maths Problem. Engineering Council, London.

http://www.engc.org.uk/engcdocuments/intern et/Website/Measuring\%20the\%20Mathematic \%20Problems.pdf 